\section{Periapical radiography using bisect technique in autistic children through nonpharmacological approach: a case report}

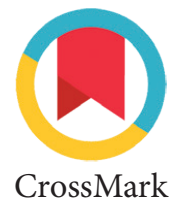

\author{
Yohanes Hutasoit, ${ }^{1 *}$ Ria N. Firman, ${ }^{1}$ Arlette Suzy ${ }^{2}$
}

Methods: In this case, dental imaging using bisect technique for autistic children is performed using modified technique for periapical and occlusal imaging as well as nonpharmacological approach.

Result: Theradiograph examination for autistic children using modified technique can be done successfully.

Conclusion: Dental radiographin autistic children canbe performed by modifying periapical radiograph using bisecting technique with nonpharmacological approach.
'Departement of Dentomaxillofacial Radiology, Faculty of Dentistry, Padjadjaran University Bandung, Indonesia

${ }^{2}$ Departement of Pedodontics, Faculty of Dentistry, Padjadjaran University, Bandung, Indonesia

*Correspondence to:

Yohanes Hutasoit,

papaluqman@gmail.com

Received 25 May 2017

Revised 30 May 2017

Accepted 21 June 2017

Available online 01 August 2017

Keywords: Autistic, Modified technique for periapical and occlusal radiograph, Nonpharmacological approach

Cite this Article: Hutasoit Y, Firman RN, Suzy A. 2017. Periapical radiography using bisect technique in autistic children through nonpharmacological approach: a case report. Journal of Dentomaxillofacial Science 2(2): 135-138. D0I:10.15562/jdmfs.v2i2.532

\section{Introduction}

Autism is a developmental disorder that is very complex and severe with widely varied alleged cause and its clinical symptoms usually appear in the first three years of a child's life. Originally thought to be psychosis, autistic disturbances due to affective contact are termed as infantile autism. Various symptoms of autism in childhood were greatly solitude (enjoyed playing alone), delayed in language development, memorizing things without thinking, limited spontaneous activity, fixed formed, obsessed with anxiety, fear of change, poor eye contact, poor relationships with others and preferred a picture or an inanimate object causing disturbance in the social life. ${ }^{1-3}$

According to the latest update by the Centers for Disease Control and Prevention (CDC) in the U.S., about one in 88 children suffers from autism, which is 1.7 times more than that reported 10 years ago. The dental caries was significantly higher in autism children so they required oral and dental care and in some circumstances $\mathrm{x}$-ray were required for diagnosis and determining treatment plan. ${ }^{4}$

\section{Case Report}

A seven-year-old boy presented to Dental Hospital Department of Pedodontic Faculty of Dentistry Padjadjaran University, Bandung with complaints of a cavity on the bottom left posterior teeth without pain. Parents wanted the tooth treated.

The patient had previously been diagnosed with autism at the age of two years and eight months and is currently undergoing occupational therapy. The general state was good, did not have a history of seizures, and did not suffer severe illness during the last six months.

Prior to treatment, he was referred to Dental Hospital Department of Radiology Faculty of Dentistry Padjadjaran University in order to get periapical radiograph taken. The technique used was bisecting technique for reasons of patient's condition. A periapical radiograph was taken for the first left mandibular molar (74) with clinical diagnosis of periapical abscess due to pulp necrosis.

Radiograph taking were divided into two visits with the following details. The first visit took place on March 18, 2006 at 11:00 until 11:30. The patient was picked up from his home by a car and the patient was accompanied by his aunt. History of the patient visit according to the author's note was as follows: the patient's condition: patient was in healthy condition during the first visit. The attitude of the patient in the vehicle was fairly quiet. Sometimes patient said words uttered by his friends at school, introduction: arriving at the Hospital, patient was directly introduced to the team of doctors who would handle the radiograph taking, 


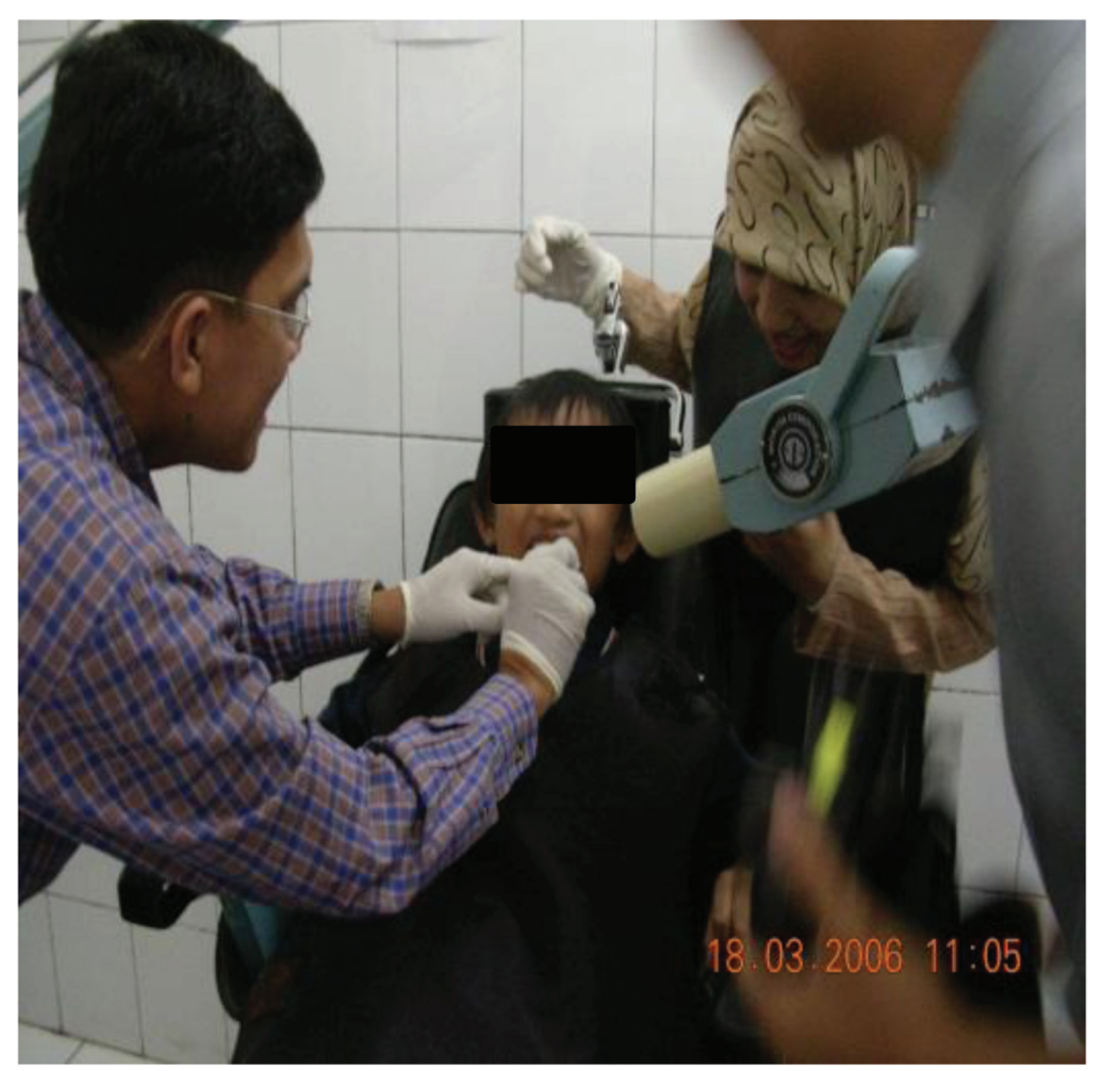

Figure 1 Patient during film placement

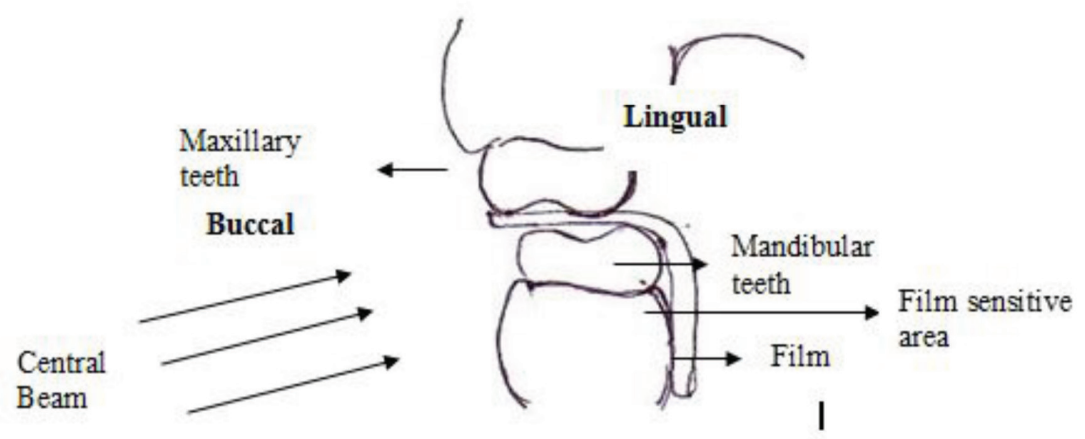

Figure 2 Modification scheme of periapical radiograph

and also introduced to the environment in which treatment would take place.

The patient was invited to wander and to look around. The patient's condition seemed hyperactive, approach during bisecting technique and radiograph taking: patient was invited to the place of radiograph taking and seated in the dental chair, an apron was worn to the patient. The patient was instructed to talk while looking at the tools that were introduced by the operator. The technique used was bisecting technique with modifications, using folded film as shown in figure 2:10 and the patient was instructed to bite the film. This was told to the patient slowly. For each successful instruction, the patient was given a nice compliment. The method used was "tell-show-do".
The patient was told to bite the film, and then instructed to open his mouth and was exemplified by the operator. During the preparation, patient's aunt accompanied the patient in the room. Obstacles: obstacles experienced during the first visit were the patient feltun comfortable when he bit the film because it was a foreign object so that the film was removed from the mouth. This was done five times, and the patient was hyperactive so that patient always wanted to leave the room and ran out of the room. Results: on the first visit, radiograph taking was not managed to be conducted due to various obstacles mentioned. However, the patient has been able to know the neighborhood, the team doctor in charge and the actions to be taken.

The second visit took place on March 25, 2006 at 11:00 until 11:30. The patient was picked up from his home by a car and the patient was accompanied by his mother. The history of the patient visit according to the author's note was as follows: the patient's condition; patient was in healthy condition when he was taken during the second visit. The attitude of the patient in the vehicle was fairly quiet. Sometimes patient said words uttered by his friends at school.

Approach during bisecting technique and radiograph taking; the day prior to the radiograph taking, a dentist who would take care of the patient's teeth had to train the patient so that the next day the patient could bite the film well. When in the Radiology Clinic the patient was invited immediately in to the room since the patient had already been familiar with the neighborhood and the teams, it was proved fromhow the patient quietly sat in the dental chair and wore an apron. The patient's condition was calm.

During the preparation figure 1, patient's mother accompanied the patient in the room. During radiograph taking, an assistant stayed inside the room for holding patient's head to prevent him from moving. Obstacles occurred during the second visit included the removal of the film from the mouth by the patient himself. The preparation stage was repeated three times before radiograph was successfully taken.

The technique used was bisecting technique with modifications, using folded film as shown in figure 2 and the patient was instructed to bite the film. The technique was done with specific upper and lower jaw angle table 1. This was told to the patient slowly. For each successful instruction, the patient was given a nice compliment. The method used was tell-show-do. The patient was instructed to bite the film, and then instructed to open his mouth and was exemplified by the operator. The radiograph was successfully taken on the second visit and the patient was given a puzzle as reward as seen in figure 3. 
Table 1 Upper and lower jaw cone angles ${ }^{12}$

\begin{tabular}{lcccccc}
\hline Maxillary & $\begin{array}{c}\text { Horizontal } \\
\text { angle }\end{array}$ & $\begin{array}{c}\text { Vertical } \\
\text { angle }\end{array}$ & & Mandible & $\begin{array}{c}\text { Horizontal } \\
\text { angle }\end{array}$ & $\begin{array}{c}\text { Vertical } \\
\text { angle }\end{array}$ \\
\hline Incisors & $0^{\circ}$ & $55-65^{\circ}$ & Incisors & $0^{\circ}$ & $(-15)-(-30)^{\circ}$ \\
Caninus & $45^{\circ}$ & $45-60^{\circ}$ & Caninus & $45^{\circ}$ & $(-15)-(-30)^{\circ}$ \\
Premolar & $75^{\circ}$ & $35-40^{\circ}$ & Premolar & $75^{\circ}$ & $(-5)-(-10)^{\circ}$ \\
Molar & $90^{\circ}$ & $25-30^{\circ}$ & Molar & $90^{\circ}$ & $0^{\circ}$ \\
\hline
\end{tabular}

The radiograph was interpreted as follows: tooth number was 74 , crown radiolucent from distal to the furcation, root missing distal root, mesial root within normal condition, periodontal membrane disappear, lamina dura disappear, alveolar crest decreased to the apical, furcation diffuse radiolucent, periapical tooth buds of teeth number 34 and 35 , impression abnormality on each element and radiological suspect was furcation involvement on tooth number 74 .

\section{Discussion}

The approach to dental care in children with autism may be conducted in two ways: non-pharmacological and pharmacological approaches. Prior to treatment it was recommended for dentists to consult with parents about the child's behavior or personality and ability to speak. Patient should be involved during consultation to enable the dentist to understand the child's condition. ${ }^{5,6}$

Fundamental aspects to be paid attention to are for nonpharmacological aspects: orientation, waiting room, short meeting during the same day, instruction and reward and punishment. The child and his parents were invited to the hospital prior to treatment to get to know the environment and devices used in treatment. Multiple visits were necessary for the patient to adapt with the new environment. Treatment was started from the simplest treatment followed by more complicated stages following the patient's adaptation with the environment. Practice at home with parents was important prior to treatment. ${ }^{5,6}$

Pharmacological approaches in autistic children include: premedication; usually the drugs used during premedication are diazepam, hydroxyzine, chloral hydrate, meperidine and promethazine. The advantage of using drugs during premedication is acceptable by all people because it is easy, due to low cost, no need to use needles, syringes, or equipment, and no special training required. $\mathrm{N}_{2} \mathrm{O}-\mathrm{O}_{2}$ sedation; children with anxiety may need $\mathrm{N}_{2} \mathrm{O}-\mathrm{O}_{2}$ sedation during treatment. The use of $\mathrm{N}_{2} \mathrm{O}-\mathrm{O}_{2}$ in some circumstances helped to increase the tolerance of children to dental care and make it

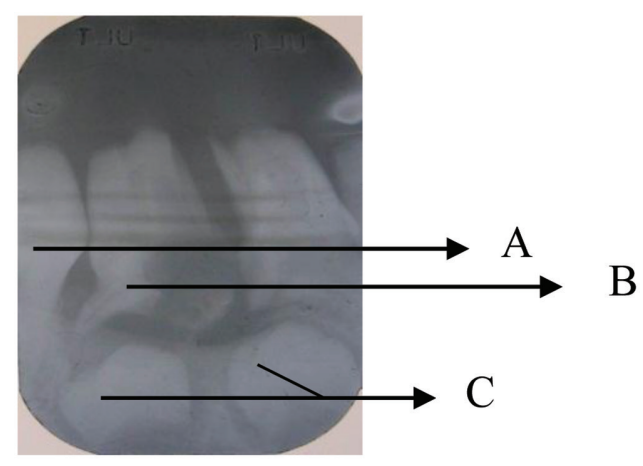

Figure 3 Result of periapical radiograph of patient $\mathrm{H}$. A. The first left mandibular molar (74), B. Caries, and $\mathrm{C}$. The first and second permanent premolar tooth buds (34

for dentists to communicate. Pharmacological approach with these drugs should be consulted with the treating physician. ${ }^{5-7}$

\section{Bisecting Technique}

Bisecting or Short-cone technique was first used for dental radiography. The concept came from the application of isometry rules, i.e. a theory known as the Cieszynski'srule of isometry. The technique was used to see the crowns, roots, bones, and the hidden surrounding tissues with special upper and lower jaw cone angle. . $, 9,12^{2}$

The bisecting technique cannot be used in children especially with the condition of anxiety and fear. These circumstances restrict the patient from handling the film by himself. The film is placed in such a way by using the patient's own teeth. For example the anterior teeth can be $\mathrm{x}$ rayed using periapical films and occlusal films. The posterior region can be $\mathrm{x}$-rayed by folding the film to form an angle perpendicular and by placing into the mouth like a bitewing technique. ${ }^{11,12}$

\section{Conclusion}

Dental radiograph in autistic children could be performed by modifying periapical radiograph using bisecting technique with nonpharmacological approach.

\section{Conflict of Interest}

The authors report no conflict of interest.

\section{References}

1. Thomas, Nithya A, Priya S, et al. Barriers to dental care for children with autism spectrum disorder. A pilot study. J Dent\& Medical Sci 2016;15: 100-105. 
2. Rosman NP. Autism: behavioral and developmental pediatrics ahand book for primary case. Boston: Little Brown Company; 2015. p. 78-84.

3. Behrman RE, Vaughan VC. Nelson ilmu kesehatan anak (Nelson: textbook of pediatrics). 12th ed. Jakarta: EGC; 1992. p. 115-124.

4. Chan DFY, Shy C, HK SO, et al. Dental health of preschool children with autism spectrum disorder in Hong Kong. HKJ Paediatr2014;19: 161-168.

5. Darby ML, Walsh MM. Dental hygiene theory and practice. 4th ed. St. Louis: WB Saunders Company; 2015. p. 122-128.

6. Andlaw RJ, Rock WP. Perawatan gigi anak (amanual of paedodontics). 2nd ed. Widya Medika; 1992. p. 15-26.

7. Malamed SF. Sedation aguide to patient management. 6thed. St. Louis: Mosby Inc; 2013. p. 277- 279.
8. White SC, Pharoah MJ. Oral radiology principles and interpretation. 7th ed. St Louis: MosbyInc; 2014. p. 91115.

9. Whaites E, Drage N. Essentials of dental radiography and radiology. 5th ed. Elsevier; 2013. p. 85-116.

10. Sitam S. Radiografi periapikal. EGC; 2012. p. 20-22.

11. Madan K, Sudhindra B, Nilima T, et al. Recent advances in dental radiography for pediatric patients: A review2015;1: 21-25.

12. Finn SB. Roentgenography: clinical pedodontics. 4th ed. Philadelphia: WB Saunders Company; 1991. p. 80-89.

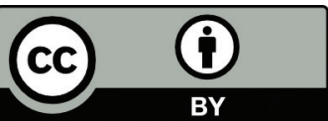

This work is licensed under a Creative Commons Attribution 